\title{
Investigation of Engine Performance using Emulsified Diesel fuel
}

\author{
Nikunj S Patel ${ }^{1}$, Prof. Maulik A Modi ${ }^{2}$, Dr. Tushar M Patel ${ }^{3}$ \\ ${ }^{l}$ (ME Scholar, Mechanical Department, LDRP-ITR, Gandhinagar, India) \\ ${ }^{2}$ (Assistant Professor, Mechanical Department, LDRP-ITR, Gandhinagar, India) \\ ${ }^{3}$ (Professor, Mechanical Department, LDRP-ITR, Gandhinagar, India)
}

\begin{abstract}
This investigation was carried out to find the replacement of diesel fuel for achieving the better performance with reduction of emissions from exhaust. The main task of research was to mix water with diesel and make stable emulsion fuel using various types of surfactants for achieving the good performance of engine as well as reduce the exhaust emissions from it. ED5( 93\% Diesel, 5\% Water, 1\% Span 20, and 1\% Tween 80) and ED10 (88\% Diesel, 10\% water, 1\% Span 20, and 1\% Tween 80) were made. These two fuels were stable in nature. So these both fuels were used as fuel in engine and results were obtained. The performance characteristics of pure diesel is compared with ED5 and ED10 by taking different parameters such as brake power (BP), specific fuel consumption (S.F.C.), and thermal efficiency.
\end{abstract}

Keywords: Diesel engine, Micro-explosion, Performance, Span-tween, Water-diesel emulsion

\section{Introduction}

Diesel engine (C.I) and petrol engine (S.I) are the main class of I.C engine. Diesel engine has excellent efficiency, fine durability, fuel saving, and more power than the petrol engine. So diesel engine primarily used in heavy duty work. Diesel engine mostly used in transporting, industrial, and agricultural and power generating sector [1]. Diesel engine has large number of assets but it generates large quantity of pollutants which is harmful for humans. Diesel engine is a primarily source of black smoke, particulate matters (PM), sulfur dioxide $\left(\mathrm{SO}_{2}\right)$, carbon dioxide $\left(\mathrm{CO}_{2}\right)$, carbon monoxide $(\mathrm{CO})$. Combustion of fossils fuels is the main contributor to the change of climate [2]. Researchers have to improve the efficiency of diesel engines and also lower the exhaust emissions from engine. $\mathrm{NO}_{\mathrm{X}}$ can be reduced by EGR but it level up the soot (PM) formation. Another method is to increase the percentage of oxygen, it lowers the level of soot (PM) formation but on other hand there is addition in $\mathrm{NO}_{\mathrm{x}}$ emissions. We cannot combine these both methods because of their high cost. There are basically four techniques of introducing water into combustion chamber. 1. by circulating water into engine entering air 2.Adding water droplet directly into combustion chamber with separate injectors. 3. Blend the air and water before the injection (unstable emulsion). 4. Blend of $\mathrm{H}_{2} \mathrm{O}$ and diesel as proper stable emulsion [3]. W/D emulsion is one of the best methods to lower the pollutants from engine exhaust and optimize efficiency of engine. W/D emulsion works as fuel in C.I engine. No any modification required in engine [4]. It is mainly used for pure and clean combustion. Presence of water lowers nitrogen oxides (NOx) and soot (PM) formation. Water reduces the combustion flame temperature hence it reduces NOx production [5].

\section{Making of Water-Diesel Emulsive Fuel}

When water and diesel blended directly, diesel arrives at top and water goes at bottom because diesel has lower density than the water. Prof. B Hopkinson invented use of water in diesel emulsion in C.I engine for increase the thermal efficiency and lower the exhaust emissions of engines. Emulsive fuel is mixture of two completely immiscible liquids which are not blend completely. In emulsion one liquid is completely divided throughout the other liquid [1]. By using required surfactants (emulsifiers) these two liquids can be bound together. Surfactant is the compound which reduces the tension between the two substances which are immiscible. It bound them together to make a good stable emulsion. Surfactants are helpful to make kinetically stable W/D emulsion fuel. It decreases the tension between molecules of water and diesel. Interface surface tension among two liquids, solids, and gases reduced by the surfactants. In water diesel emulsion, water mixes homogeneously with the diesel on volume basis. A surfactant is helpful to make stable emulsion. [6] This W/D emulsion doesn't need any modification in engine so it is very useful fuel to use. Emulsions are mainly categorized into two types. One is water in oil emulsion and other is oil in water emulsion (Fig. 1). Water in diesel emulsion comes under the water in oil emulsion type. In Water - oil emulsion there is continues phase of oil and water is uniformly distributed. In oil in water emulsion there is continues phase of water and oil is uniformly distributed through it. [7] 


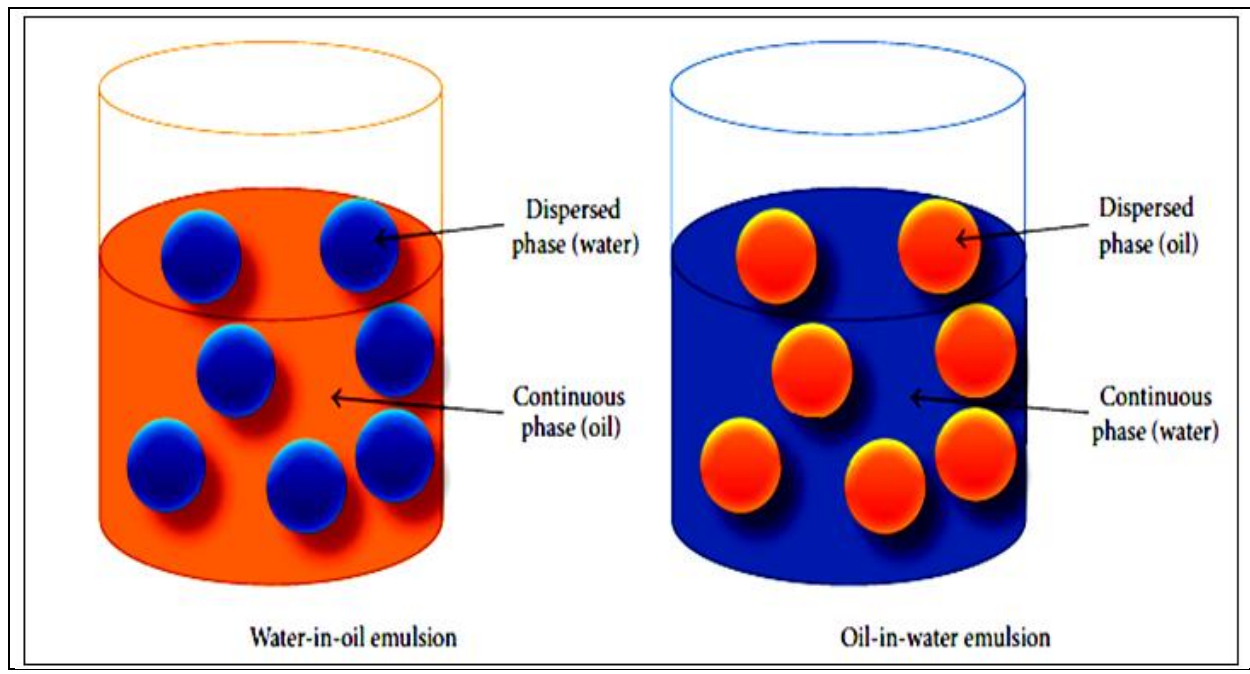

Fig. 1: Two phase water in oil and oil in water emulsion [7]

Table 1: HLB value for different type of emulsions [2]

\begin{tabular}{|c|l|}
\hline HLB value & Type of Emulsion \\
\hline$<10$ & Lipid-soluble (water-insoluble) \\
\hline$>10$ & Water-soluble (lipid-insoluble) \\
\hline $4-8$ & Antifoaming agents \\
\hline $7-12$ & Water in oil emulsifier \\
\hline $13-16$ & Oil in water emulsifier \\
\hline $11-14$ & Wetting agents \\
\hline $12-15$ & Detergents \\
\hline $16-20$ & Solubilize and hydro trope \\
\hline
\end{tabular}

For making proper stable emulsion, main task was to select proper surfactant or mixture of surfactants. Water in diesel emulsion comes under the water in oil emulsion. So the surfactant should have HLB value in range of $7-$ 12. Emulsion making was trial and error method. Stability of prepared emulsion was checked after that.

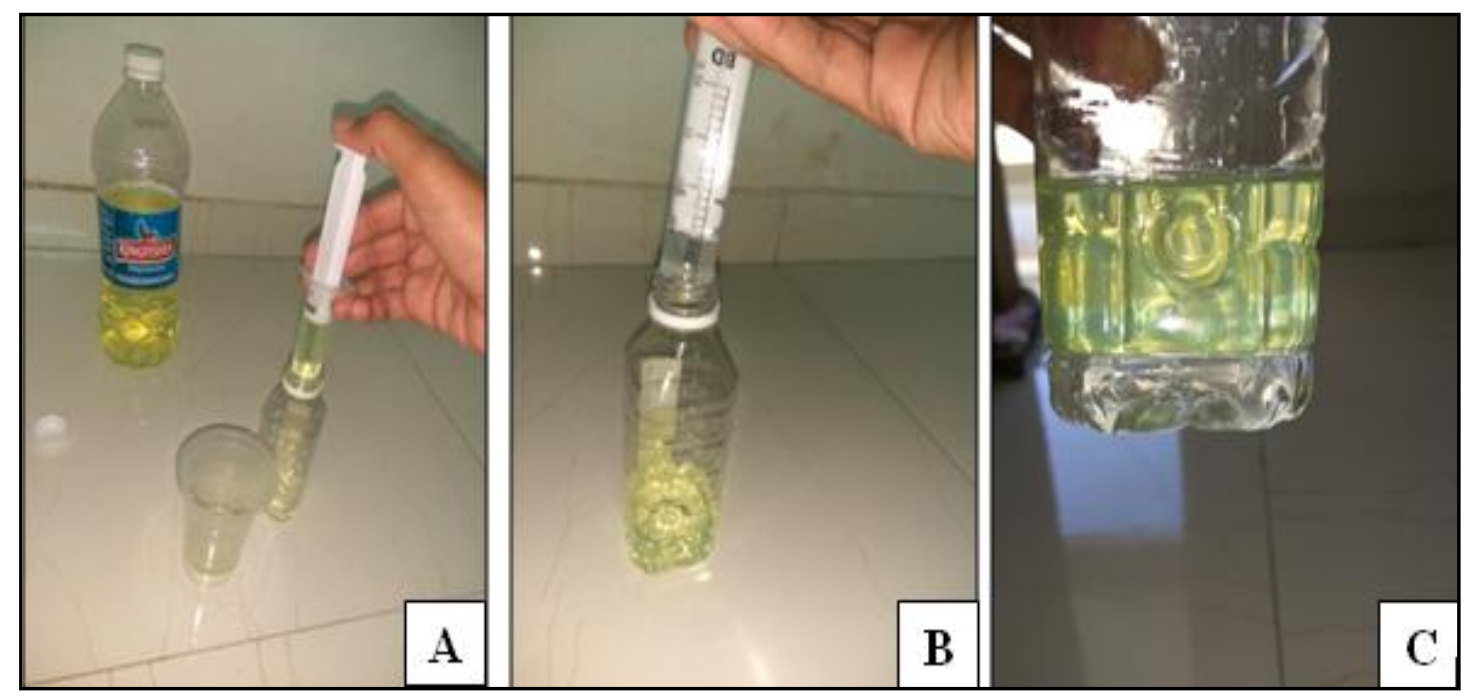

Fig. 2: Mixing of water and diesel

Measured volume of diesel poured into bottle with the help of injection as shown in Fig. 2 (A). Then measured quantity of water added to the bottle as shown in Fig. 2 (B). But due to density difference between diesel and water, diesel came upside and water went to downside in bottle. Diesel has lower density than the water. They both are immiscible liquids. 


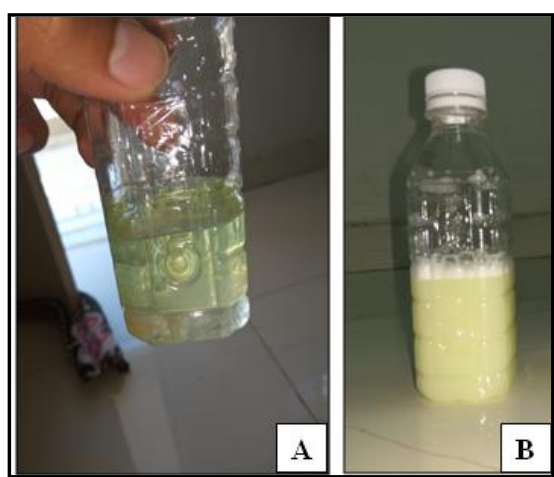

Fig. 3: Emulsion with span 20 as surfactant

Now for making proper stable emulsion using water and diesel, span 20 was added with measured volume as shown in Fig. 3 (A). Then bottle was stirred properly for around 5 to 10 minutes. Then emulsion obtained using span 20 as surfactant (Bottle A) was checked for stability. Fig. 3 (B) Same process was repeated for making emulsion with tween 20 as surfactant. Emulsion obtained using tween 20 as surfactant (Bottle B) was also checked for stability as shown in Fig. 4.

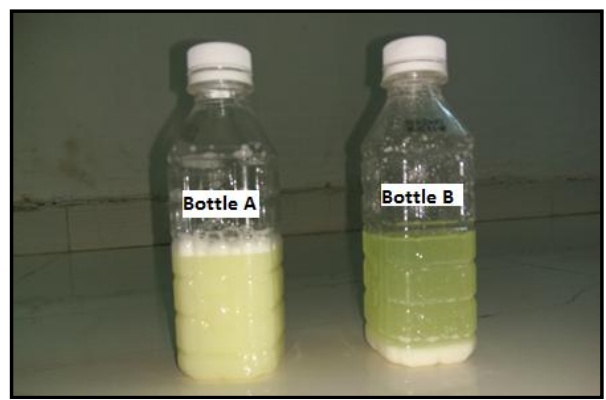

Fig. 4: Emulsion fuel using span 20 (Bottle A) and tween 20 (Bottle B) as surfactant

As seen from Fig. 4 the emulsions made with the help of span 20 and tween 20 as surfactants were not stable. There was separation of water and diesel. So those emulsions can't be used as fuel in engine. Now emulsion was made using mixture of surfactants. $1 \%$ span 20 and $1 \%$ tween 80 were used to make water -diesel emulsive fuel. Using this mixture of surfactants two different emulsions were made with $5 \%$ water content and $10 \%$ water content. ED5 has 5\% water content and ED10 has $10 \%$ water content.

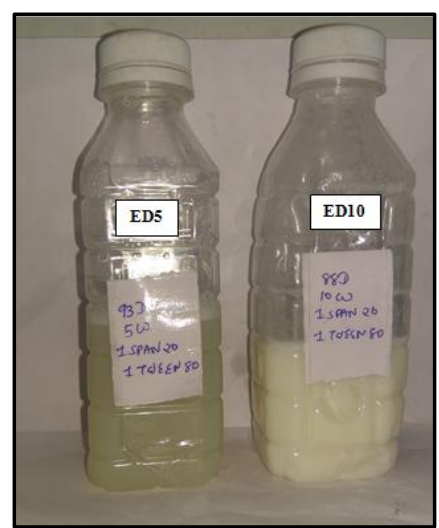

Fig. 5: ED5 and ED10 emulsion

Table 2: Comparison of Fuel Properties

\begin{tabular}{|l|c|c|}
\hline \multicolumn{1}{|c|}{ Fuel } & Calorific Value (kJ/kg) & Density (kg/m3) \\
\hline Diesel & 42850 & 833 \\
\hline ED5 (93\% Diesel,5\%Water,1\%Span20,1\%Tween80) & 39225 & 846 \\
\hline ED10 (88\% Diesel,10\%Water,1\%Span20,1\%Tween80) & 36766 & 854 \\
\hline
\end{tabular}




\section{Experimental Setup}

Various parameters were listed below for doing experiment on research diesel engine. Load was varied in range of $1-13 \mathrm{~kg}$.

Table 3: Variable Parameters for Experiments

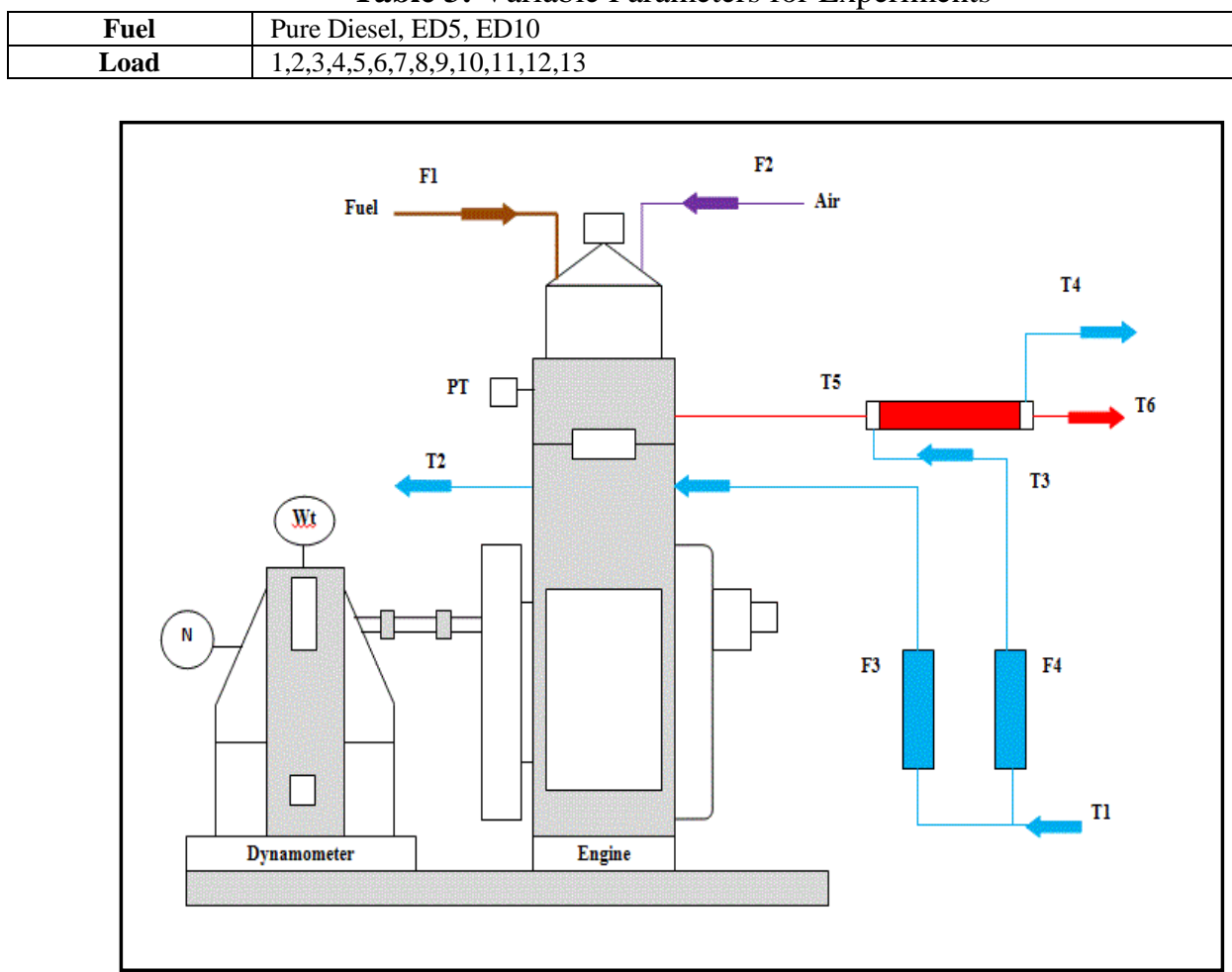

Fig. 6: Schematic diagram of experimental setup

In Fig. 6 schematic diagram of experimental setup is shown. It includes single cylinder, four stroke, multi-fuel, research engine connected to eddy current type dynamometer for loading. The operation mode of the engine can be changed from diesel to petrol or from petrol to diesel with some necessary changes. In both modes the compression ratio can be varied without stopping the engine and without altering the combustion chamber geometry by specially designed tilting cylinder block arrangement. Instruments are provided to interface airflow, fuel flow, temperatures and load measurements.

Table 4: Description of symbols used in schematic diagram

\begin{tabular}{|c|l|}
\hline Symbol & Sensor Name \\
\hline F1, F2 & Fuel flow and air flow sensors \\
\hline F3, F4 & Engine water flow and calorimeter water flow \\
\hline $\mathrm{W}$ & Load sensor \\
\hline $\mathrm{N}$ & Engine speed sensor \\
\hline $\mathrm{PT}$ & Cylinder pressure and Injection pressure sensor \\
\hline $\mathrm{T} 1, \mathrm{~T} 2$ & Jacket water inlet and outlet temperature ${ }^{\circ} \mathrm{C}$ \\
\hline $\mathrm{T} 3, \mathrm{~T} 4$ & Calorimeter water inlet and outlet temperature ${ }^{\circ} \mathrm{C}$ \\
\hline $\mathrm{T} 4$ & Calorimeter water outlet temperature ${ }^{\circ} \mathrm{C}$ \\
\hline $\mathrm{T} 5$ & Exhaust gas to calorimeter inlet temperature ${ }^{\circ} \mathrm{C}$ \\
\hline $\mathrm{T} 6$ & Exhaust gas from calorimeter outlet temperature oC \\
\hline
\end{tabular}

Table 5: Engine specification

\begin{tabular}{|c|l|}
\hline Product & Research Engine test setup 1 cylinder, 4 stroke, Multifuel Computerized \\
\hline No. of cylinder & 1 \\
\hline Type of cooling & Water cooled \\
\hline Rated power & $3.5 \mathrm{~kW}$ @ $1500 \mathrm{rpm}$ \\
\hline Cylinder diameter & $87.5 \mathrm{~mm}$ \\
\hline Orifice diameter & $20 \mathrm{~mm}$ \\
\hline Stroke length & $110 \mathrm{~mm}$ \\
\hline CR Range & $12: 1-18: 1$ \\
\hline Connecting rod length & $234 \mathrm{~mm}$ \\
\hline Dynamometer & Type eddy current, water cooled, with loading unit \\
\hline Injection variation & $0-25$ Deg BTDC \\
\hline
\end{tabular}




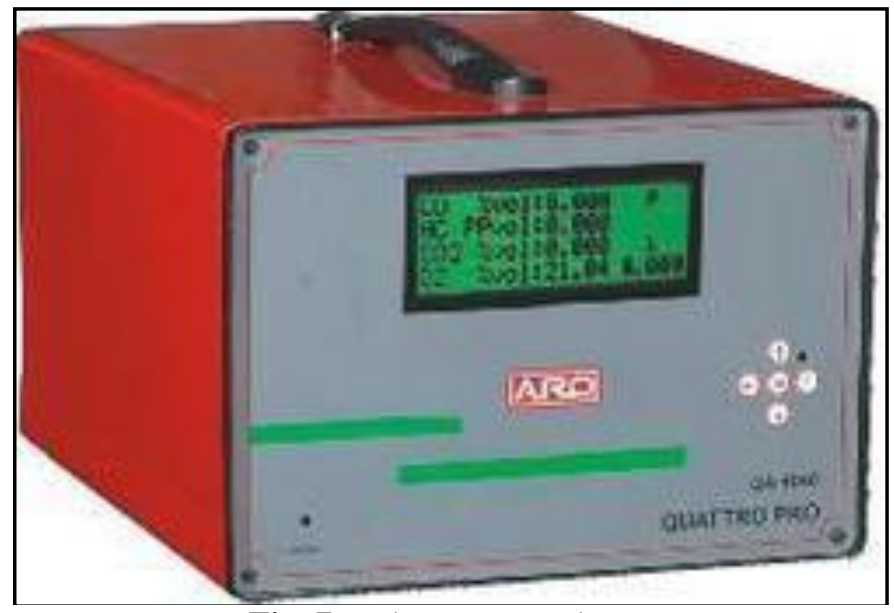

Fig. 7: Exhaust gas analyzer

Exhaust gas analyzer is shown in Fig. 7. Exhaust gas analyzer is used to measure the level of pollutants in the exhaust of the car. Exhaust gas analyzer is also used to tune an engine for optimum mileage. Exhaust gas analyzer is also applicable to measure the function of catalytic converters. Exhaust gas analyzer is used in various governments authorized test centers. Exhaust gas analyzer specifications are shown in Table 6.

Table 6: Specification of exhaust gas analyzer

\begin{tabular}{|c|c|c|c|c|}
\hline & Specified range & Accuracy Volume & Accuracy & Resolution \\
\hline $\mathbf{C O}$ & $0-10 \%$ & $0.06 \%$ & $3 \%$ & $0.01 \%$ \\
\hline $\mathbf{H C}$ & $0-20000 \mathrm{PPM}$ & $12 \mathrm{PPM}$ & $5 \%$ & $1 \mathrm{PPM}$ \\
\hline $\mathbf{C O}_{\mathbf{2}}$ & $0-20 \%$ & $0.4 \%$ & $4 \%$ & $0.1 \%$ \\
\hline $\mathbf{O}_{2}$ & $0-21 \%$ & $0.1 \%$ & $3 \%$ & $0.01 \%$ \\
\hline NO & $0-5000 \mathrm{PPM}$ & $25 \mathrm{PPM}$ & $5 \%$ & $1 \mathrm{PPM}$ \\
\hline Lambda & $0-9.99$ & - & - & 0.001 \\
\hline RPM & $200-6000 \mathrm{RPM}$ & $10 \mathrm{RPM}$ & - & $1 \mathrm{RPM}$ \\
\hline Oil Temperature & $0-150{ }^{\circ} \mathrm{C}$ & $0.20^{\circ} \mathrm{C}$ & $0.3 \%$ & $1.00{ }^{\circ} \mathrm{C}$ \\
\hline
\end{tabular}

In this experiment, diesel engine was used and connected with the eddy current dynamometer with the help of dynamometer. Load was varied on the engine. Exhaust gas analyzer was used to find the emission characteristic of exhaust gas. The readings were taken by varying the load on the engine using the dynamometer. Engine performance such as break power, indicated power, break specific fuel consumption, fuel consumption etc. found from the experiments. First pure diesel fuel was used and emission characteristics and engine performance was taken. Then the water-Diesel emulsive fuel with 5\% water concentration (ED5) and 10\% water content (ED10) were used to find the emission characteristics and engine performance of the engine.

\section{Result Table}

Table 7: Result table for the Pure Diesel

\begin{tabular}{|c|c|c|c|c|c|c|c|c|c|c|}
\hline $\begin{array}{l}\text { Sr. } \\
\text { No. }\end{array}$ & $\begin{array}{c}\text { Load } \\
(\mathrm{kg})\end{array}$ & $\begin{array}{c}\text { Torque } \\
(\mathrm{Nm})\end{array}$ & $\begin{array}{c}\mathbf{I P} \\
(\mathbf{k W})\end{array}$ & $\begin{array}{c}\text { BP } \\
(\mathbf{k W}) \\
\end{array}$ & $\begin{array}{c}\mathbf{F P} \\
(\mathbf{k W})\end{array}$ & $\begin{array}{l}\eta_{\text {ite }} \\
(\%)\end{array}$ & $\begin{array}{l}\eta_{\text {bte }} \\
(\%)\end{array}$ & $\begin{array}{c}\eta_{\text {mech }} \\
(\%)\end{array}$ & $\begin{array}{l}\eta_{\text {vol }} \\
(\%)\end{array}$ & $\begin{array}{c}\text { SFC } \\
(\mathrm{kg} / \mathrm{kWh})\end{array}$ \\
\hline 1 & 0.97 & 1.76 & 1.95 & 0.28 & 1.67 & 40.96 & 5.94 & 14.36 & 69.28 & 1.41 \\
\hline 2 & 1.98 & 3.59 & 2.25 & 0.58 & 1.67 & 42.01 & 10.83 & 25.78 & 69.14 & 0.78 \\
\hline 3 & 3.01 & 5.46 & 2.54 & 0.87 & 1.67 & 42.68 & 14.69 & 34.25 & 69.11 & 0.57 \\
\hline 4 & 3.79 & 6.89 & 2.76 & 1.09 & 1.67 & 46.38 & 18.24 & 39.49 & 69.23 & 0.46 \\
\hline 5 & 4.96 & 9 & 3.08 & 1.41 & 1.67 & 43.13 & 19.75 & 45.78 & 69 & 0.43 \\
\hline 6 & 5.92 & 10.74 & 3.32 & 1.65 & 1.67 & 46.49 & 23.14 & 49.70 & 69.04 & 0.36 \\
\hline 7 & 7.04 & 12.78 & 3.63 & 1.96 & 1.67 & 43.57 & 23.58 & 53.99 & 69 & 0.36 \\
\hline 8 & 8 & 14.51 & 3.89 & 2.22 & 1.67 & 43.58 & 24.9 & 57.07 & 68.74 & 0.34 \\
\hline 9 & 9.07 & 16.47 & 4.2 & 2.53 & 1.67 & 44.11 & 26.6 & 60.24 & 68.63 & 0.32 \\
\hline 10 & 10.08 & 18.3 & 4.48 & 2.81 & 1.67 & 44.28 & 27.78 & 62.72 & 68.34 & 0.3 \\
\hline 11 & 11.65 & 21.14 & 4.89 & 3.22 & 1.67 & 45.65 & 30.04 & 65.85 & 68.49 & 0.28 \\
\hline 12 & 11.96 & 21.7 & 4.97 & 3.3 & 1.67 & 41.75 & 27.75 & 66.40 & 68.07 & 0.3 \\
\hline 13 & 13.04 & 23.66 & 5.28 & 3.61 & 1.67 & 42.25 & 28.87 & 68.37 & 67.91 & 0.29 \\
\hline
\end{tabular}


Table 8: Result table for the ED5 as fuel

\begin{tabular}{|c|c|c|c|c|c|c|c|c|c|c|}
\hline $\begin{array}{c}\text { Sr. } \\
\mathbf{N o} .\end{array}$ & $\begin{array}{c}\text { Load } \\
(\mathbf{k g})\end{array}$ & $\begin{array}{c}\text { Torque } \\
(\mathbf{N m})\end{array}$ & $\begin{array}{c}\mathbf{I P} \\
(\mathbf{k W})\end{array}$ & $\begin{array}{c}\mathbf{B P} \\
(\mathbf{k W})\end{array}$ & $\begin{array}{c}\mathbf{F P} \\
(\mathbf{k W})\end{array}$ & $\begin{array}{c}\mathbf{\eta}_{\text {ite }} \\
(\boldsymbol{\%})\end{array}$ & $\begin{array}{c}\mathbf{\eta}_{\mathbf{b t e}} \\
(\boldsymbol{\%})\end{array}$ & $\begin{array}{c}\mathbf{\eta}_{\mathbf{m e c h}} \\
(\boldsymbol{\%})\end{array}$ & $\begin{array}{c}\mathbf{\eta}_{\text {vol }} \\
(\boldsymbol{\%})\end{array}$ & $\begin{array}{c}\text { SFC } \\
(\mathbf{k g} / \mathbf{k W h})\end{array}$ \\
\hline 1 & 1.08 & 1.95 & 2.11 & 0.31 & 1.80 & 43.03 & 6.32 & 14.69 & 69.35 & 1.46 \\
\hline 2 & 2.05 & 3.73 & 2.39 & 0.59 & 1.80 & 47.68 & 11.77 & 24.69 & 69.45 & 0.77 \\
\hline 3 & 3.00 & 5.45 & 2.67 & 0.87 & 1.80 & 48.05 & 15.66 & 32.58 & 69.57 & 0.58 \\
\hline 4 & 4.00 & 7.26 & 2.96 & 1.16 & 1.80 & 44.53 & 17.45 & 39.19 & 69.45 & 0.53 \\
\hline 5 & 5.21 & 9.46 & 3.31 & 1.51 & 1.80 & 49.80 & 22.72 & 45.62 & 69.06 & 0.40 \\
\hline 6 & 6.01 & 10.91 & 3.50 & 1.70 & 1.80 & 48.67 & 23.64 & 48.57 & 69.22 & 0.39 \\
\hline 7 & 7.12 & 12.92 & 3.81 & 2.01 & 1.80 & 46.01 & 24.27 & 52.76 & 69.30 & 0.38 \\
\hline 8 & 8.10 & 14.71 & 4.06 & 2.26 & 1.80 & 46.00 & 25.61 & 55.67 & 69.07 & 0.36 \\
\hline 9 & 9.03 & 16.37 & 4.33 & 2.53 & 1.80 & 46.21 & 27.00 & 58.43 & 68.94 & 0.34 \\
\hline 10 & 9.97 & 18.10 & 4.57 & 2.77 & 1.80 & 46.09 & 27.94 & 60.61 & 68.84 & 0.33 \\
\hline 11 & 11.01 & 19.98 & 4.80 & 3.00 & 1.80 & 45.89 & 28.68 & 62.50 & 68.78 & 0.32 \\
\hline 12 & 11.81 & 21.44 & 5.01 & 3.21 & 1.80 & 45.08 & 28.88 & 64.07 & 68.63 & 0.32 \\
\hline 13 & 13.03 & 23.65 & 5.45 & 3.65 & 1.80 & 47.64 & 31.90 & 66.97 & 68.87 & 0.29 \\
\hline
\end{tabular}

Table 10: Result table for the ED10 as fuel

\begin{tabular}{|c|c|c|c|c|c|c|c|c|c|c|}
\hline $\begin{array}{c}\text { Sr. } \\
\text { No. }\end{array}$ & $\begin{array}{c}\text { Load } \\
(\mathbf{k g})\end{array}$ & $\begin{array}{c}\text { Torque } \\
(\mathbf{N m})\end{array}$ & $\begin{array}{c}\mathbf{I P} \\
(\mathbf{k W})\end{array}$ & $\begin{array}{c}\mathbf{B P} \\
\mathbf{( k W )}\end{array}$ & $\begin{array}{c}\mathbf{F P} \\
(\mathbf{k W})\end{array}$ & $\begin{array}{c}\mathbf{\eta}_{\text {ite }} \\
(\boldsymbol{\%})\end{array}$ & $\begin{array}{c}\mathbf{\eta}_{\text {bte }} \\
(\boldsymbol{\%})\end{array}$ & $\begin{array}{c}\mathbf{\eta}_{\text {mech }} \\
(\boldsymbol{\%})\end{array}$ & $\begin{array}{c}\mathbf{\eta}_{\text {vol }} \\
(\boldsymbol{\%})\end{array}$ & $\begin{array}{c}\text { SFC } \\
(\mathbf{k g} / \mathbf{k W h})\end{array}$ \\
\hline 1 & 1.01 & 1.84 & 1.62 & 0.3 & 1.32 & 38.69 & 7.16 & 18.52 & 69.32 & 1.37 \\
\hline 2 & 2.01 & 3.66 & 1.9 & 0.58 & 1.32 & 40.44 & 12.35 & 30.53 & 69.6 & 0.79 \\
\hline 3 & 3.08 & 5.59 & 2.21 & 0.89 & 1.32 & 42.43 & 17.09 & 40.27 & 69.43 & 0.58 \\
\hline 4 & 4.04 & 7.33 & 2.47 & 1.15 & 1.32 & 43.19 & 20.11 & 46.56 & 69.68 & 0.49 \\
\hline 5 & 5.14 & 9.33 & 2.79 & 1.47 & 1.32 & 44.78 & 23.60 & 52.69 & 69.38 & 0.42 \\
\hline 6 & 6.06 & 11 & 3.05 & 1.73 & 1.32 & 44.57 & 25.28 & 56.72 & 68.44 & 0.38 \\
\hline 7 & 7.13 & 12.94 & 3.34 & 2.02 & 1.32 & 45.42 & 27.47 & 60.48 & 68.97 & 0.35 \\
\hline 8 & 7.89 & 14.31 & 3.52 & 2.2 & 1.32 & 41.03 & 25.64 & 62.50 & 69.31 & 0.38 \\
\hline 9 & 9.04 & 16.41 & 3.84 & 2.52 & 1.32 & 43.22 & 28.36 & 65.63 & 69 & 0.35 \\
\hline 10 & 10.01 & 18.17 & 4.06 & 2.74 & 1.32 & 43.21 & 29.16 & 67.49 & 69.12 & 0.34 \\
\hline 11 & 10.93 & 19.84 & 4.31 & 2.99 & 1.32 & 43.51 & 30.18 & 69.37 & 68.93 & 0.33 \\
\hline 12 & 12.03 & 21.82 & 4.62 & 3.3 & 1.32 & 41.89 & 29.92 & 71.43 & 68.58 & 0.33 \\
\hline 13 & 13.15 & 23.87 & 4.93 & 3.61 & 1.32 & 40.91 & 29.96 & 73.23 & 68.5 & 0.33 \\
\hline
\end{tabular}

\section{Result And Discussion}

5.1 Brake Power (BP)

\section{BP vs Load}

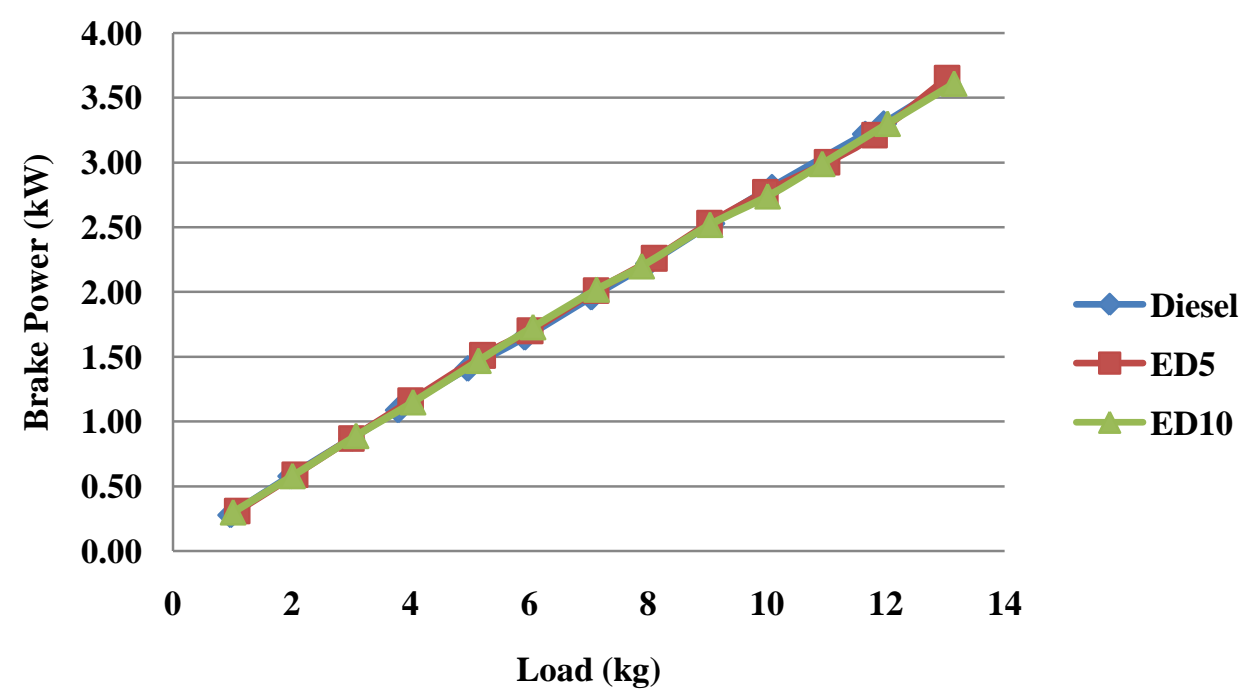

Fig. 8: Comparison of brake power for Diesel, ED5 and ED10 at various loads

Brake power for all three fuels increase as there was increase in load. From above graph it is clear that there is no large difference in brake power of all three fuels diesel and water - diesel emulsive fuels. So it is concluded that brake power doesn't depends on type of fuel. It only depends on the load given by dynamometer. 


\subsection{Specific Fuel Consumption (SFC)}

Fig. 9 shows the variation of specific fuel consumption with load at various percentage of water concentration in the diesel. From this graph it is clear that the ED5 has high specific fuel consumption up to load of $12 \mathrm{~kg}$. At low load the SFC of diesel is lowest. ED10 has more SFC than the diesel and low SFC than ED5. At medium load SFC for ED10 lower than the diesel. After that as load increases the SFC of ED10 increases and at load of $12 \mathrm{~kg}$ it is higher than ED5.

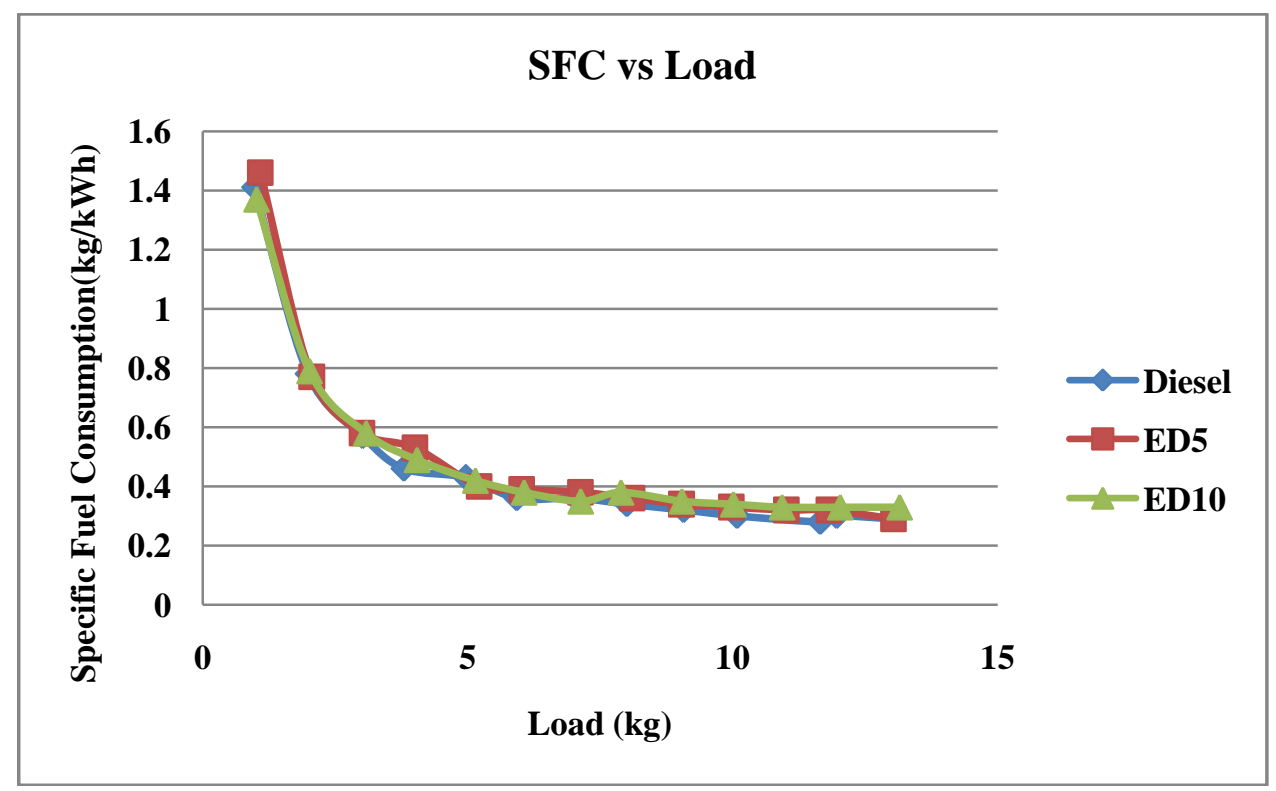

Fig. 9: Comparison of SFC for Diesel, ED5 and ED10 at various loads

\subsection{Indicated Power (IP)}

From this graph it is clearly seen that the indicated power for ED5 emulsion fuel is more than the diesel at all load condition. But ED10 has lower indicated power than the pure diesel at all loads. As the load increases, the indicated power for all three fuels increases. As water percentage is $10 \%$ in diesel there may be more reduction in the flame temperature than the essential requirement. So there may be incomplete combustion of fuel in case of ED10 and so it shows less indicated power.

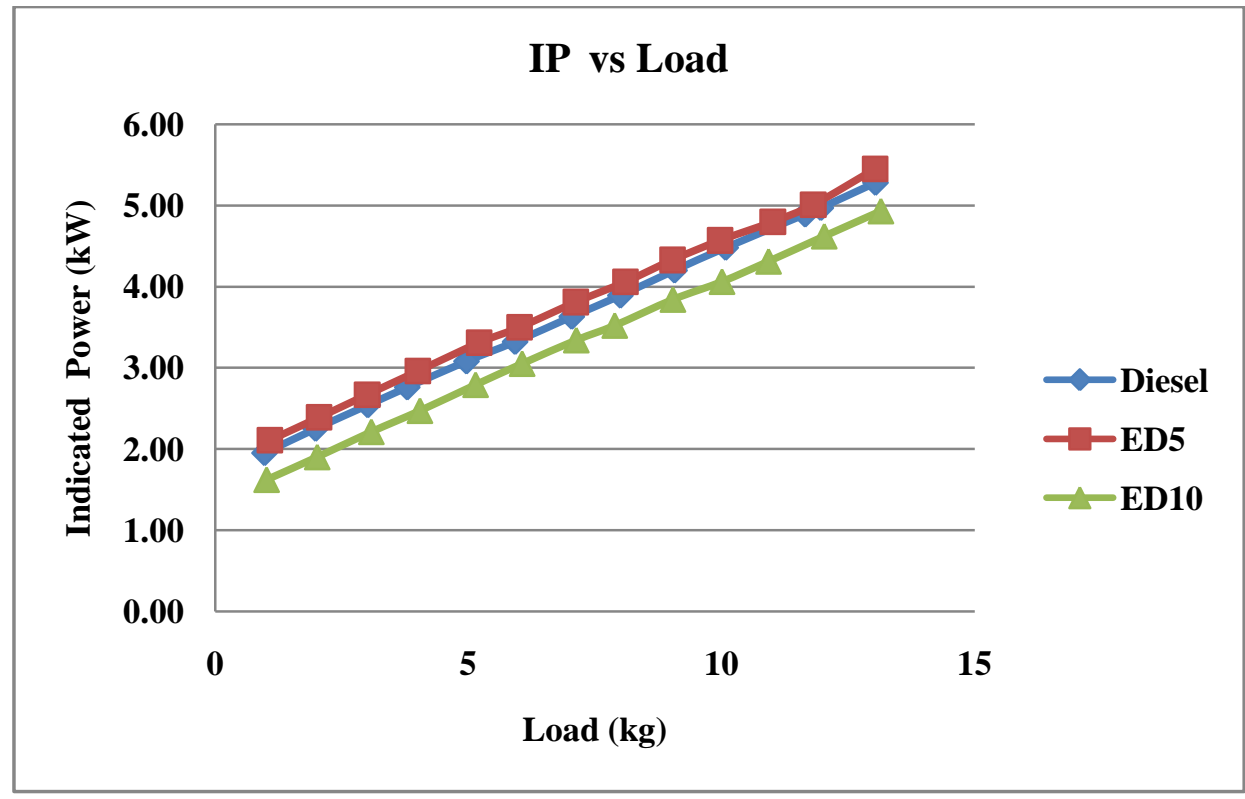

Fig. 9: Comparison of indicated power for Diesel, ED5 and ED10 at various loads 


\subsection{Brake Thermal Efficiency $\left(\boldsymbol{n}_{\mathrm{bte}}\right)$}

It is the defined as the ratio of brake power to the product of fuel consumption and calorific value. The change in brake thermal efficiency versus load is shown in graph. As shown in graph at lower range load the brake thermal efficiency for emulsive fuels is higher than pure diesel. Calorific value of emulsion fuel was low but specific fuel consumption was high than the diesel. Presence of water in fuel produces more expansion work and also due to secondary atomization there was slight more brake thermal efficiency.

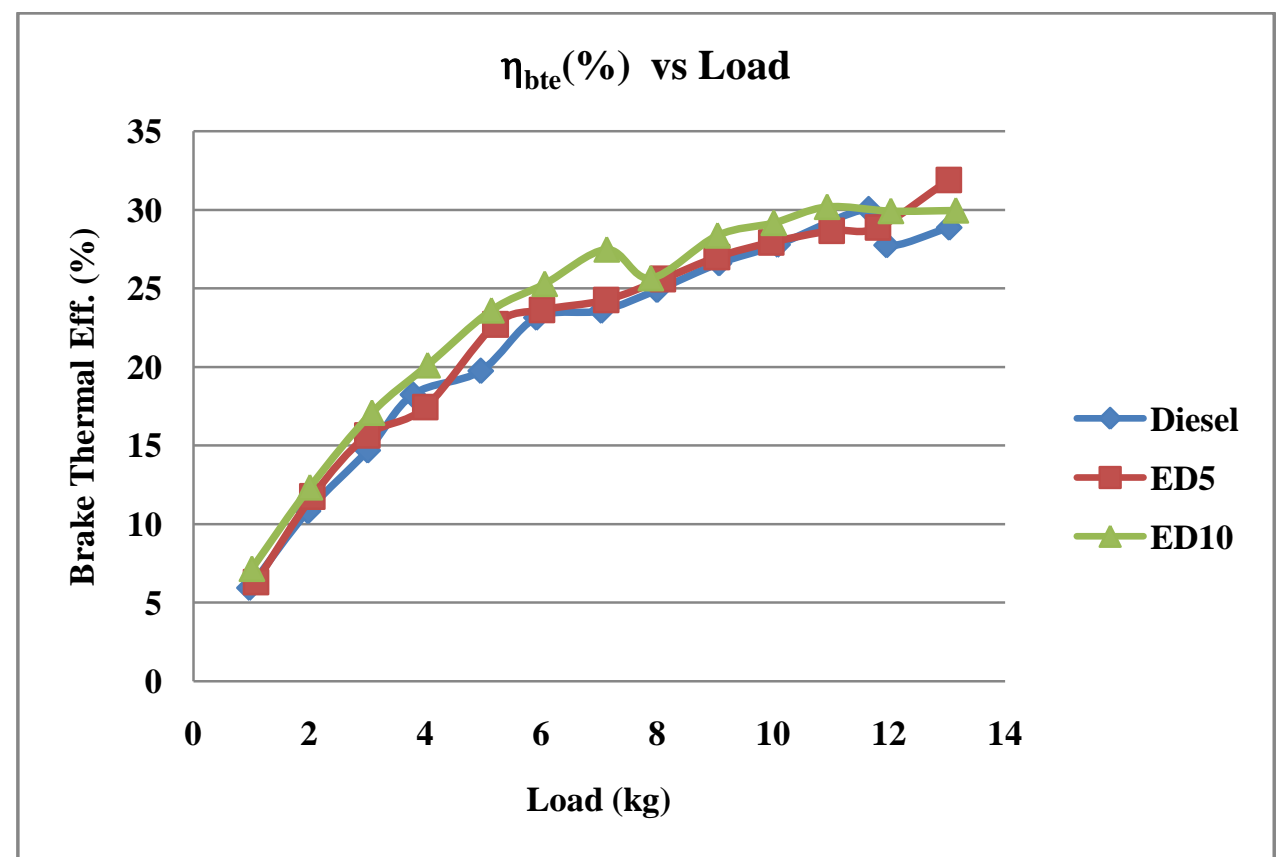

Fig. 10: Comparison of brake thermal efficiency for Diesel, ED5 and ED10 at various loads

\subsection{Mechanical Efficiency $\left(\boldsymbol{\eta}_{\text {mech }}\right)$}

The variations of mechanical efficiency with load under different water contents are shown in Fig. 11. Mechanical efficiency is defined as the ratio of power available on the shaft to the power developed in the engine means it is a ratio of brake power to the indicated power. From the graph it is clear that the mechanical efficiency for all three fuels increases as the load increase. From the graph it can be concluded that the mechanical efficiency of ED10 is highest for all loads. And as the load increase the mechanical efficiency of all the fuels increase. Diesel has mechanical efficiency more than ED5 and less than ED10. So from this graph ED10 is good replacement for diesel for improving mechanical efficiency. As the water content increases the expansion work of water is more. And also due to amount of water there is second atomization due to vaporization of it and it improves atomization of fuel.

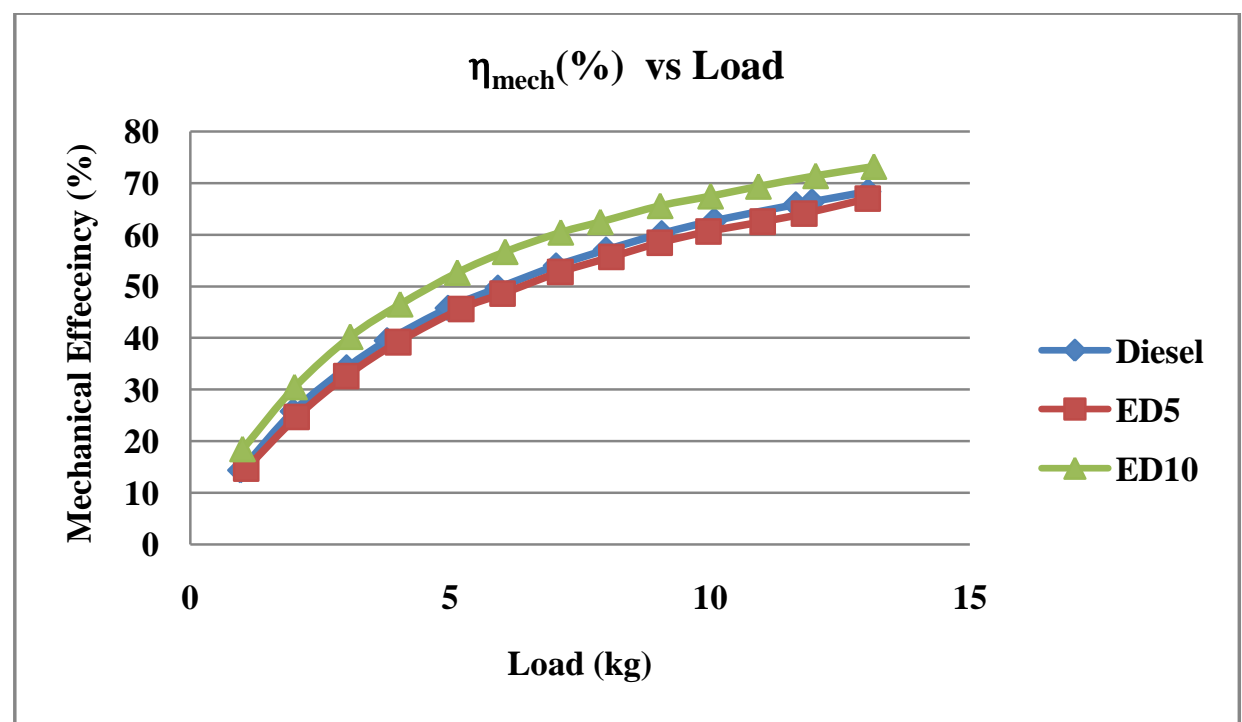

Fig. 11: Comparison of mechanical efficiency for Diesel, ED5 and ED10 at various loads 


\subsection{Indicated Thermal Efficiency $\left(\eta_{\text {ite }}\right)$}

As seen from graph there is up and down for indicated thermal efficiency for all three fuels. But for all loads, there is high indicated thermal efficiency in ED5 emulsive fuel than the diesel and ED10. There is around $8 \%$ high indicated thermal efficiency in emulsion fuel because the indicated power produced by W/D emulsion fuel is higher than pure diesel and ED10.

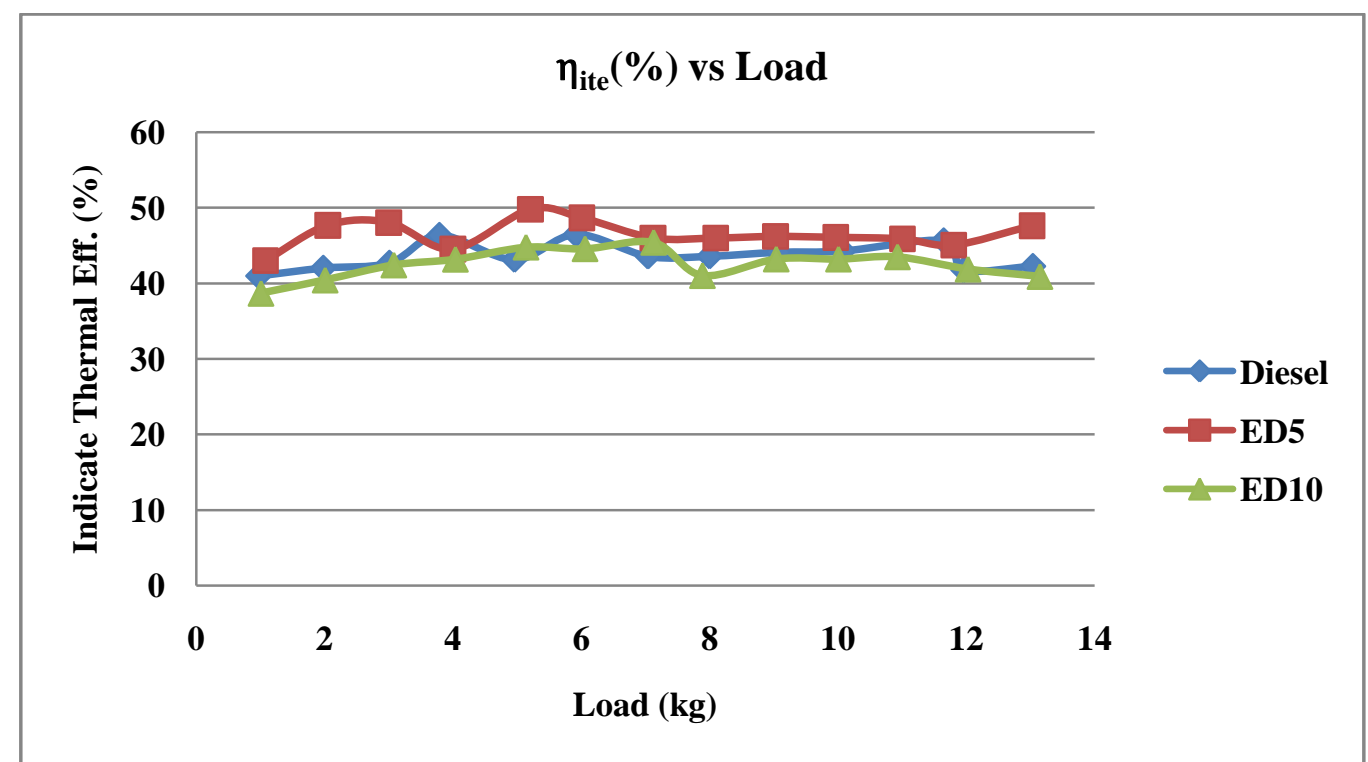

Fig. 12: Comparison of indicated thermal efficiency for Diesel, ED5 and ED10 at various loads

\section{Conclusion}

By comparing performance characteristics of all three fuels it is conclude that the indicated power and indicated thermal efficiency is higher for ED5 emulsion fuel than diesel. But the friction power for emulsion fuel is more so the brake power becomes equal for both fuels. Brake thermal efficiency is higher for ED5 emulsion fuel but mechanical efficiency is higher for diesel fuel. For ED10 brake thermal efficiency and mechanical efficiency is highest for all loads but fuel consumption is also high because as percentage of water content increase the calorific value decrease.

By making emulsions with different water content and using different surfactants, optimization value can be obtained and compared with pure diesel. By making nano emulsion using mechanical agitation and ultrasonic method, stability of emulsion can be improved. Nano emulsion also improves the performance characteristics and emissions characteristics.

\section{Acknowledgements}

I am very thankful to all those who helped me for the successful completion of the literature review and for providing valuable guidance throughout the semester. I would like to thank Assistant Professor Maulik A Modi, Professor Dr. Tushar M Patel and our department of mechanical engineering, LDRP - ITR, gandhinagar. Their constant support, encouragement, and constructive criticism have been invaluable assets through my research work.

\section{References}

[1] W. J. Ithnin, A. M., Ahmad, M. A., Bakar, M. A. A., Rajoo, S. Yahya, "Combustion performance and emission analysis of diesel engine fuelled with water-in-diesel emulsion fuel made from low-grade diesel fuel," Energy Convers. Manag., vol. 90, pp. 375-382, 2015.

[2] S. Vellaiyan and K. S. Amirthagadeswaran, "The role of water-in-diesel emulsion and its additives on diesel engine performance and emission levels: A retrospective review," Alexandria Eng. J., vol. 55, no. 3, pp. 2463-2472, 2016.

[3] S. Patel, G. P. Rathod, and T. M. Patel, "Water Injection Effects On Performance Characteristics Of A Ci Engine," vol. 11, no. 3 , pp. 66-70, 2014

[4] A. Maiboom and X. Tauzia, "NOx and PM emissions reduction on an automotive HSDI Diesel engine with water-in-diesel emulsion and EGR: An experimental study," Fuel, vol. 90, no. 11, pp. 3179-3192, 2011.

[5] S. Patel, G. P. Rathod, and T. M. Patel, "Experimental investigation of diesel engine with water injection system on emission parameters," vol. 11, no. 2, pp. 47-51, 2014

[6] A. Peramanan, K. Saravanakumar, M. Sethuram, and K. Shajahan, "Effect of Hydro Emulsification in Diesel Engine," pp. 18-22, 2015.

[7] M. Yahaya Khan, Z. A. Abdul Karim, F. Y. Hagos, A. R. A. Aziz, and I. M. Tan, "Current trends in water-in-diesel emulsion as a fuel," Sci. World J., vol. 2014, no. January, 2014. 